\title{
Nonlinear Amplification Model in RC Frame Structures: Case Study for Chi-Chi Earthquake
}

\author{
Ravinder Kumar Agrahari", K. K. Pathak \\ Department of Civil Engineering, Indian Institute of Technology (BHU), India
}

Received April 4, 2021; Revised May 14, 2021; Accepted June 15, 2021

\section{Cite This Paper in the following Citation Styles}

(a): [1] Ravinder Kumar Agrahari, K. K. Pathak, "Nonlinear Amplification Model in RC Frame Structures: Case Study for Chi-Chi Earthquake," Civil Engineering and Architecture, Vol. 9, No. 4, pp. 1156-1169, 2021. DOI: 10.13189/cea.2021.090417.

(b): Ravinder Kumar Agrahari, K. K. Pathak (2021). Nonlinear Amplification Model in RC Frame Structures: Case Study for Chi-Chi Earthquake. Civil Engineering and Architecture, 9(4), 1156-1169. DOI: 10.13189/cea.2021.090417.

Copyright $\mathrm{C} 2021$ by authors, all rights reserved. Authors agree that this article remains permanently open access under the terms of the Creative Commons Attribution License 4.0 International License

\begin{abstract}
For the seismic design of non-structural components (NSCs), more awareness is required not only for prevention of catastrophic impact of human life but also for saving the economical crises. Due to the seismic ground motion, an inertia force acts upon the primary structure as well as non-structural components. The inertia force which affects the NSCs is related to the acceleration amplification factor. Various researchers presented the amplification factor as a function of the normalized height of the structures, but it is found that the amplification factor depends on other factors as well. In this paper, non-linear acceleration amplification models are proposed, which not only depends on the normalized height of the structure but also on the range of ground acceleration and the natural period of the structures. For this, five moments resisting RC frame models of 2,4,6,8 and 10 storeys are considered. A large number of ground motion data, having the range of less than $0.067 \mathrm{~g}$, twenty-nine ground motion data in the range of $0.067 \mathrm{~g}$ to $0.2 \mathrm{~g}$ and twenty-four ground motion data in the range of $0.2 \mathrm{~g}$ to $0.3 \mathrm{~g}$ respectively are accounted. Linear time history method is used for the analysis of all models. Based on the results, the non-linear amplification model is proposed and compared with the previously reported models.
\end{abstract}

Keywords Time History Analysis, Non-Structural Component, Floor Acceleration, Acceleration Amplification Factor

\section{Introduction}

Taiwan, situated on the western circum Pacific seismic belt region, is regularly affected by the seismic hazard. As reported by the central weather bureau (CWB), every year nearly 18500 earthquake events occur in Taiwan [1]. In 1999, Chi-chi earthquake caused more than 9000 buildings collapsed. Major losses were occurred not only in terms of social or economic but also affected the life of the people [2]. In terms of damages of structures, some buildings were RC structures and brick masonry buildings. Massive damages were observed on account of NSCs [3].

All the major earthquakes in the world such as Alaska [4], Loma prieta [5] [6], San Fernando [7], Northridge [8] [9], and Darfield [10] have shown that the non-structure elements of the structure were more affected during the seismic action. Sometimes the reparing costs of the non-structural elements are more than the primary components of the structures [11] [12] [13] [14] after the seismic hazard.

The non-structural component of the structures is divided based on the acceleration sensitivities and storey drift sensitivities [15]. Masonry walls, doors, windows partitions etc. are the example of the NSCs based on the storey drift sensitive, similarly parapets, boilers, suspended ceilings etc. are the examples of the NSCs based on the acceleration sensitive [16]. For the design of the secondary elements of the structures, floor amplification factor, is an important parameter for the estimation of maximum inertia force on the structure. Some of the pioneering literature, reported on the 
behaviour of the secondary elements of the structures are explained.

ASCE7-10 [17] code describes the design process of the seismic force act on the non-structural components. Drake and Bachman [18] used the concept of the ASCE code and gave the relationship between the peak ground acceleration (PGA) and the peak floor acceleration (PFA). Darke and Bachman, were considered many recorded time history data sets. This large number of data set compiled and obtained the relationship from 16 California earthquake ground motion data. These data sets were derived by taking the average of the PFA in each direction. To obtain the relationship between the PFA and PGA, the average values of PFA was divided by the average value of PGA in each direction. Finally, results were compared with the NEHRP provisions.

Gillengerten and Bachman [19] gave a concept of the acceleration amplification factor considering the major changes of the NEHRP provisions observed in the 1997 edition. The equation of the acceleration amplification factor is the same as given in ASCE 7-05 [20] and ASCE 7-10 [17]. They observed that the acceleration amplification factor " $[1+2(\mathrm{z} / \mathrm{h})]$ " was bounded between the mean plus standard deviation of the peak acceleration.

Saeed Fathali et al. [21], investigated the acceleration amplification factor and the component amplification factor, with the concept of mean plus standard deviation (Mean + SD). They considered 73 different ground motion data with different ground motion range of less than $0.067 \mathrm{~g}, 0.067 \mathrm{~g}$ to $0.2 \mathrm{~g}$ and more than $0.2 \mathrm{~g}$. Finally, they proposed the non-linear acceleration amplification formula and compared with the provisions given by ASCE code.

In another approach, Crescenzo Petrone et al. [22], considered the five different heights of moment-resisting RC frame models, designed by Euro code 8 . The linear and non-linear methods were used to analyze of these models. It was found that the Euro code formula for analysis of amplification factors gave conservative results compared to the analytical results.

Surana et al. [23], examined the peak floor acceleration and compared with the different codes (ASCE, EN 1998, NZS 1170.4 and IS 1893) and observed that for low rise buildings (up to 4 storeys) the amplification values performed linear behaviour. After that its behaviors were nonlinear. It was also found that the peak floor acceleration demand at the top of the building is decreases as the natural period of the structures increases.
In this paper, non-linear acceleration amplification models are proposed for moment-resisting RC frames buildings having the natural fundamental periods between 0.1 to 1.5 second. For the analysis, the model mass participation ratio higher than $90 \%$ are considered as per ASCE provisions. The seismic ground motion data are considered in the range of $0.01 \mathrm{~g}$ to $0.32 \mathrm{~g}$. Based on the Mean + SD acceleration amplification results, to propose the amplification model and compared with the previous proposed models.

\section{Existing Models}

ASCE/SEI 7-05 [19] section 13.3.1, defines the lateral seismic force on the non-structural component as-

$$
\begin{gathered}
F_{p}=0.4 S_{d s} a_{p}\left(1+2 \frac{z}{h}\right)\left(\frac{I_{p}}{R_{p}}\right) W_{p} \quad(\text { ASCE/SEI 7-05 } \\
\text { Equation 13.3-1) } \\
F_{p} \leq 1.6 S_{d s} I_{p} W_{p} \quad(\text { ASCE/SEI 7-05 Equation 13.3-2) } \\
F_{p} \geq 0.3 S_{d s} I_{p} W_{p} \quad(\text { ASCE/SEI 7-05 Equation 13.3-3) }
\end{gathered}
$$

Where $F_{p}$ represents the lateral seismic design force, $S_{d s}$ is the site-specific short period spectral acceleration, $a_{p}$ denote the component amplification factor having ranged from 1.0 to $2.5, \mathrm{z}$ is the height of the component to base, $\mathrm{h}$ is the total height of the building to base, $I_{p}$ is the component important factor and $R_{p}$ is the component response modification factor which represents the energy absorbed by the component and also $\mathrm{W}_{\mathrm{p}}$ is the weight of the component.

ASCE gave the acceleration amplification factor $(\Omega)$ in terms of normalized height $(\mathrm{z} / \mathrm{h})$ of the structure. It gives a linear relation between the PFA and PGA. The codal provisions for amplification formula are given as:

$$
\Omega=1+2\left(\frac{\mathrm{z}}{\mathrm{h}}\right) .
$$

Saeed Fathali [20] gave the non-linear relationship between the acceleration amplification factor and the normalized height. It [20] considered two constants $\alpha$ and $\beta$ for obtaining the non-linear amplification factor formula to change the seismic ground motion. The observed mathematical model is given as:

$$
\Omega=\frac{P F A}{P G A}=1+\alpha\left(\frac{z}{h}\right)^{\beta},
$$

where $\alpha$ and $\beta$ are constants based on the range of the ground motion. The values of $\alpha$ and $\beta$ are given in Table 1 and 2 . 
Table 1. Values of $\alpha$ for acceleration sensitive non- structural components

\begin{tabular}{|c|c|c|c|}
\hline Time & PGA $=0.04 S_{\text {DS }}<0.067 \mathrm{~g}$ & $0.067 \mathrm{~g} \leq \mathrm{PGA}=0.04 \mathrm{~S}_{\mathrm{DS}}<0.2 \mathrm{~g}$ & $\mathrm{PGA}=0.04 \mathrm{~S}_{\mathrm{DS}} \geq 0.2 \mathrm{~g}$ \\
\hline $\mathrm{T}_{\mathrm{a}}=0.5 \mathrm{sec}$ & 2.12 & 1.93 & 1.75 \\
\hline $0.5 \mathrm{~s} \leq \mathrm{T}_{\mathrm{a}}<1.5 \mathrm{~s}$ & 2.61 & 1.55 & 1.01 \\
\hline $\mathrm{T}_{\mathrm{a}} \geq 1.5 \mathrm{~s}$ & 2.52 & 1.53 & 0.5 \\
\hline
\end{tabular}

Table 2. Values of $\beta$ for acceleration sensitive non- structural components

\begin{tabular}{|c|c|c|c|}
\hline Time & $P G A=0.04 S_{D S}<0.067 g$ & $0.067 \mathrm{~g} \leq \mathrm{PGA}=0.04 \mathrm{~S}_{\mathrm{DS}}<0.2 \mathrm{~g}$ & PGA $=0.04 S_{\mathrm{DS}} \geq 0.2 \mathrm{~g}$ \\
\hline $\mathrm{T}_{\mathrm{a}}=0.5 \mathrm{sec}$. & 0.78 & 1.25 & 0.92 \\
\hline $0.5 \mathrm{~s} \leq \mathrm{T}_{\mathrm{a}}<1.5 \mathrm{~s}$ & 1.16 & 0.75 & 0.69 \\
\hline $\mathrm{T}_{\mathrm{a}} \geq 1.5 \mathrm{~s}$ & 1.64 & 1.65 & 3.00 \\
\hline
\end{tabular}

\section{Proposed Mathematical Model}

ASCE formula is based on the normalized height of the structure only and does not depend upon the natural period of the structure. However, Fathali's model observed the acceleration amplification factor depends not only on the normalized height of the structure but also on seismic ground motion range. It was also marked that, the acceleration amplification factor was depend on the period of the structure [24]. However, it notifies that the shape of the amplification factor is nonlinear in the present case whereas the previous model performed was linear behaviour which gave conservative results. Based on these factors to propose a mathematical model shown as:

$$
\Omega=1+\left(\frac{T m a x-T}{T * a}\right) \mathrm{y}\left(y^{5}\right)^{y^{4}},
$$

where $T_{\max }$ is the maximum structural period, and the recommended value is 2.5 second [24]. $T$ is the period of supporting structure for which the peak roof acceleration is not less than PGA. " $y$ " is represented as the normalized height $(\mathrm{z} / \mathrm{h})$ of the structure, and "a" represent constant which depends upon the period of supporting structure and the seismic ground motion range. Values of "a" given in Table 3.

Table 3. Values of "a" based on ground motion range and period of supporting structure

\begin{tabular}{|c|c|c|}
\hline $\begin{array}{c}\text { Ground motion } \\
\text { acceleration }\end{array}$ & "a" & $\begin{array}{c}\text { Period of supporting } \\
\text { structure }\end{array}$ \\
\hline \multirow{3}{*}{$\mathrm{PGA}^{*}=0.04 \mathrm{~S}_{\mathrm{DS}}<0.067 \mathrm{~g}$} & 2.25 & $0<\mathrm{T}<0.5 \mathrm{sec}$ \\
\cline { 2 - 3 } & 1.1 & $0.5 \mathrm{sec} \leq \mathrm{T}<1.0 \mathrm{sec}$ \\
\cline { 2 - 3 } & 0.8 & $1.0 \mathrm{sec} \leq \mathrm{T}<1.5 \mathrm{sec}$ \\
\hline \multirow{3}{*}{$\begin{array}{c}0.067 \mathrm{~g} \leq \mathrm{PGA}=0.04 \mathrm{~S}_{\mathrm{DS}} \\
<0.2 \mathrm{~g}\end{array}$} & 2.25 & $0<\mathrm{T}<0.5 \mathrm{sec}$ \\
\cline { 2 - 3 } & 1.25 & $0.5 \mathrm{sec} \leq \mathrm{T}<1.0 \mathrm{sec}$ \\
\cline { 2 - 3 } & 0.85 & $1.0 \mathrm{sec} \leq \mathrm{T}<1.5 \mathrm{sec}$ \\
\hline \multirow{2}{*}{$\begin{array}{c}0.2 \mathrm{~g} \leq \mathrm{PGA}=0.04 \mathrm{~S}_{\mathrm{DS}} \\
<0.31 \mathrm{~g}\end{array}$} & 2.25 & $0<\mathrm{T}<0.5 \mathrm{sec}$ \\
\cline { 2 - 3 } & 1.25 & $0.5 \mathrm{sec} \leq \mathrm{T}<1.0 \mathrm{sec}$ \\
\cline { 2 - 3 } & 0.75 & $1.0 \mathrm{sec} \leq \mathrm{T}<1.5 \mathrm{sec}$ \\
\hline
\end{tabular}

The proposed mathematical model results non-linear behaviour. The non-linear general exponential function is obtained with the help of Euraqa Pro [25] software which is an artificial intelligence based power modelling engine. Euraqa pro software is mainly used to determine the mathematical equations that describe sets of data in their simplest form. For the proposed mathematical equation, first step is to determine the natural period of the structures. Next step is to obtain the non-linear equations using Euraqa pro software. Finally, is to determine the constant "a" based on intensity of ground motion and period of the supporting structures using with trials and error method and to obtain the satisfactory values given in table 3 , respectively.

\section{Building Configuration}

In this paper, five RC moment-resisting frame structures of two, four, six, eight, and ten stories are considered. The supports of the models are fixed. The first storey height is $4 \mathrm{~m}$, and subsequent storey height is $3.4 \mathrm{~m}$. The 2D models are shown in Figure 1 and the size of the beams and columns are given in Table 4 . The fundamental period of the structures lies in the ranges of 0.1 to 1.5 second and the damping ratio is $5 \%$. For the analysis of all the models, Etabs [26] software has been used.

Table 4. Size of beams and columns

\begin{tabular}{|c|c|c|}
\hline \multirow{4}{*}{ Beam } & Configuration & Size in $\mathrm{mm}$ \\
\hline & $\mathrm{B} 1$ & $300 \times 400$ \\
\cline { 2 - 3 } & $\mathrm{B} 2$ & $300 \times 450$ \\
\cline { 2 - 3 } & $\mathrm{B} 3$ & $450 \times 500$ \\
\cline { 2 - 3 } & $\mathrm{B} 4$ & $450 \times 600$ \\
\cline { 2 - 3 } & $\mathrm{B} 5$ & $450 \times 650$ \\
\hline \multirow{4}{*}{ Column } & $\mathrm{B} 6$ & $450 \times 675$ \\
\cline { 2 - 3 } & $\mathrm{C} 0$ & $300 \times 400$ \\
\cline { 2 - 3 } & $\mathrm{C} 1$ & $300 \times 450$ \\
\cline { 2 - 3 } & $\mathrm{C} 2$ & $450 \times 500$ \\
\cline { 2 - 3 } & $\mathrm{C} 3$ & $525 \times 550$ \\
\cline { 2 - 3 } & $\mathrm{C} 4$ & $550 \times 600$ \\
\cline { 2 - 3 } & $\mathrm{C} 5$ & $600 \times 700$ \\
\hline
\end{tabular}




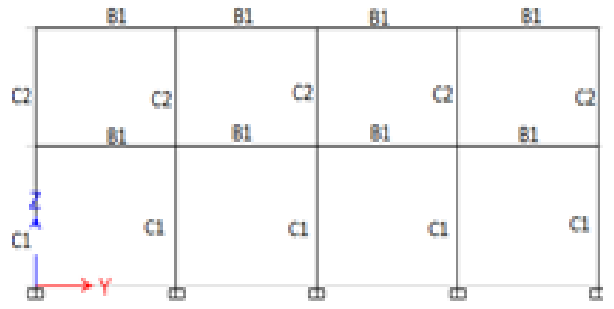

(a)

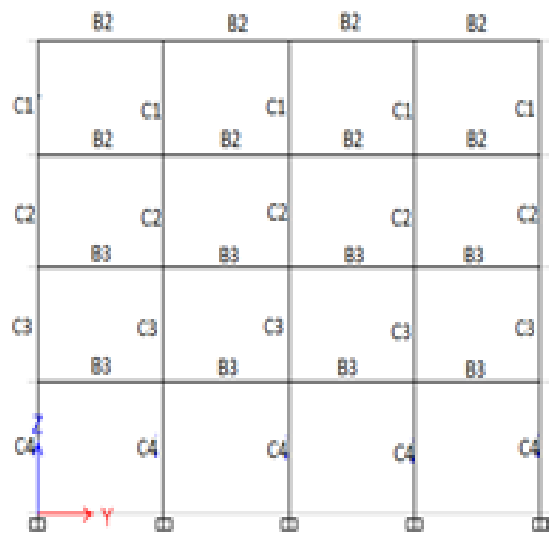

(b)

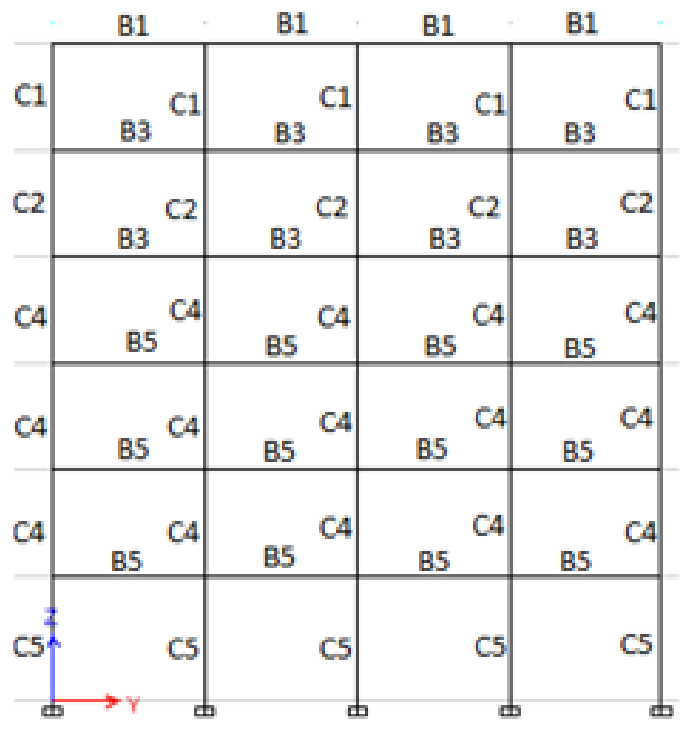

(c)

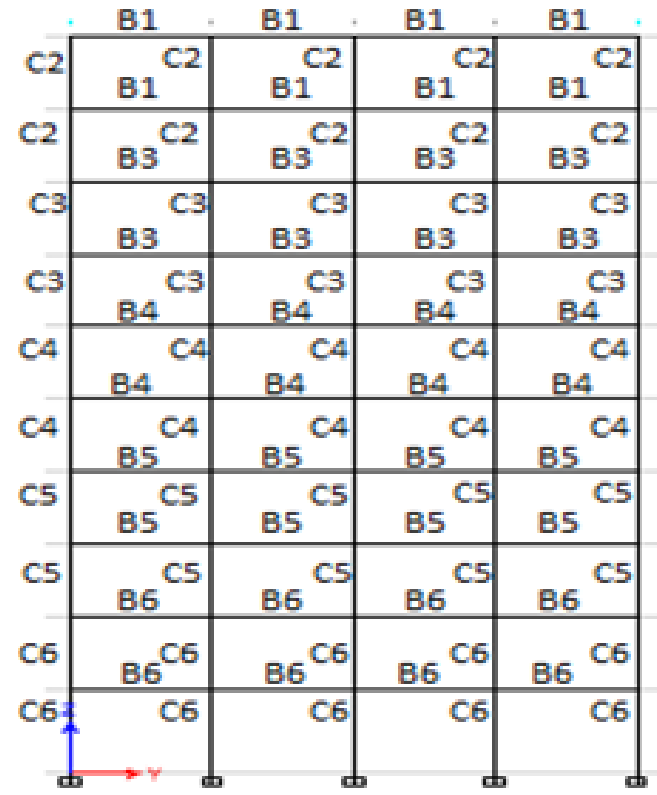

(d)

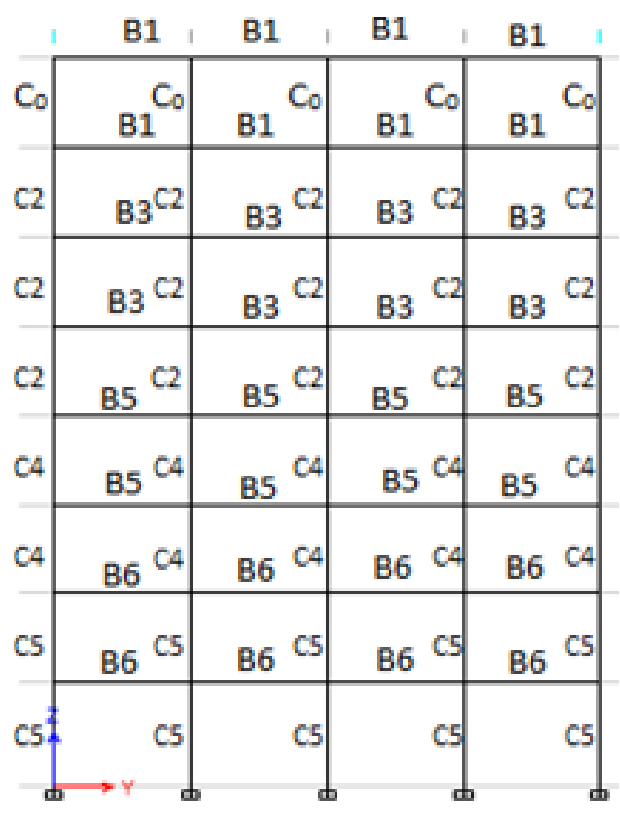

(e)

Figure 1. Moment resisting frame models (a) 2 (b) 4 (c) 6 (d) 8 and (e) 10 stories

\section{Ground Motion Selection}

Many researches worked with the higher range of the ground acceleration (higher than $0.3 \mathrm{~g}$ ), but most of the cases, the buildings are damaged at a low degree of the ground motion. Therefore, this paper is to study the behaviour of the structures with a lower range of ground acceleration $(0.01 \mathrm{~g}$ to $0.32 \mathrm{~g})$. The selection of the ground motion was obtained from the strong ground motion virtual data centre [27]. For the analysis of the models, time history data having ranges between $0.01 \mathrm{~g}$ to $0.31 \mathrm{~g}$ is taken, and it divided $(0.01 \mathrm{~g}$ to $0.067 \mathrm{~g}, 0.067 \mathrm{~g}$ to $0.2 \mathrm{~g}$ and more than $0.2 \mathrm{~g}$ ) based on Fathali [21]. In this study, 28 recorded ground motion data are between $0.01 \mathrm{~g}$ to $0.067 \mathrm{~g}$, 29 ground motion data in the range of $0.067 \mathrm{~g}$ to $0.2 \mathrm{~g}$ and 24 ground motion data are between $0.2 \mathrm{~g}$ to $0.31 \mathrm{~g}$. Details of the ground motion data are given in Table 5, 6 and 7 as below. 
Table 5. Recorded ground motion data having ranges $0.01 \mathrm{~g}$ to $0.67 \mathrm{~g}$

\begin{tabular}{cccc}
\hline Ground motion name & PGA (g) & T (sec) & T $\mathbf{p}(\mathbf{s e c})$ \\
\hline Chi-chi 1 & 0.066 & 64.992 & 16.696 \\
Chi-chi 2 & 0.057 & 52.98 & 17.005 \\
Chi-chi 3 & 0.044 & 47.975 & 15.66 \\
Chi-chi 4 & 0.047 & 47.975 & 17.14 \\
Chi-chi 5 & 0.0199 & 45.988 & 16.112 \\
Chi-chi 6 & 0.027 & 45.988 & 22.875 \\
Chi-chi 7 & 0.028 & 63.98 & 26.69 \\
Chi-chi 8 & 0.0237 & 63.98 & 15.56 \\
Chi-chi 9 & 0.0372 & 53.98 & 16.23 \\
Chi-chi 10 & 0.066 & 70.97 & 18.42 \\
Chi-chi 11 & 0.0516 & 70.97 & 17.14 \\
Chi-chi 12 & 0.0441 & 50.98 & 18.1 \\
Chi-chi 13 & 0.0352 & 50.98 & 13.73 \\
Chi-chi 14 & 0.0592 & 60.98 & 14.305 \\
Chi-chi 15 & 0.0503 & 60.98 & 16.775 \\
Chi-chi 16 & 0.0467 & 56.985 & 25.205 \\
Chi-chi 17 & 0.0492 & 56.985 & 17.275 \\
Chi-chi 18 & 0.0361 & 62.98 & 14.69 \\
Chi-chi 19 & 0.065 & 62.98 & 17.275 \\
Chi-chi 20 & 0.0662 & 74.98 & 15.656 \\
Chi-chi 21 & 0.066 & 62.98 & 18.694 \\
Chi-chi 22 & 0.0604 & 59.98 & 19.476 \\
Chi-chi 23 & 0.0574 & 59.98 & 20.66 \\
Chi-chi 24 & 0.0511 & 16.004 \\
Chi-chi 25 & 0.0514 & 62.988 & 15.872 \\
Chi-chi 26 & 0.024 & 62.988 & 20.424 \\
Chi-chi 27 & 0.0185 & 49.992 & 49.992 \\
Chi-chi 28 & 0.0439 & 56.992 & \\
\end{tabular}

Table 6. Recorded ground motion data having ranges $0.067 \mathrm{~g}$ to $0.2 \mathrm{~g}$

\begin{tabular}{cccc}
\hline Ground motion name & PGA (g) & T (sec) & $\mathbf{T}_{\mathbf{p}}(\mathbf{s e c})$ \\
\hline Chi-chi 1 & 0.1374 & 60.98 & 17.74 \\
Chi-chi 2 & 0.1348 & 60.98 & 15.93 \\
Chi-chi 3 & 0.1217 & 56.985 & 13.905 \\
Chi-chi 4 & 0.1179 & 56.985 & 15.08 \\
Chi-chi 5 & 0.1092 & 57.975 & 15.99 \\
Chi-chi 6 & 0.147 & 65.045 & 14.58 \\
Chi-chi 7 & 0.1215 & 65.045 & 14.475 \\
Chi-chi 8 & 0.1167 & 70.97 & 16.555 \\
Chi-chi 9 & 0.127 & 70.97 & 17.265 \\
Chi-chi 10 & 0.1913 & 65.045 & 16.81 \\
Chi-chi 11 & 0.1565 & 65.045 & 16.545 \\
Chi-chi 12 & 0.1654 & 65.045 & 15.6 \\
Chi-chi 13 & 0.1692 & 65.045 & 16.0 \\
Chi-chi 14 & 0.1439 & 63.985 & 14.275 \\
Chi-chi 15 & 0.1624 & 65.045 & 14.45 \\
Chi-chi 16 & 0.1517 & 65.045 & 14.73 \\
Chi-chi 17 & 0.1322 & 66.005 & 13.45 \\
Chi-chi 18 & 0.1234 & 66.005 & 16.125 \\
Chi-chi 19 & 0.1866 & 74.98 & 17.235 \\
Chi-chi 20 & 0.155 & 74.98 & 15.04 \\
Chi-chi 21 & 0.157 & 61.98 & 16.72 \\
Chi-chi 22 & 0.197 & 74.985 & 15.47 \\
Chi-chi 23 & 0.1344 & 96.985 & 11.85 \\
Chi-chi 24 & 0.1863 & 96.07 & 16.635 \\
Chi-chi 25 & 0.1563 & 93.985 & 12.685 \\
Chi-chi 26 & 0.1883 & 96.985 & 12.02 \\
Chi-chi 27 & 0.1831 & 99.03 & 10.715 \\
Chi-chi 28 & 0.1699 & 61.99 & 9.66 \\
Chi-chi 29 & 0.1829 & 71.0 & 14.38 \\
\hline
\end{tabular}


Table 7. Recorded ground motion data having ranges $0.2 \mathrm{~g}$ to $0.32 \mathrm{~g}$

\begin{tabular}{|c|c|c|c|}
\hline Ground motion name & PGA (g) & $\mathrm{T}(\mathrm{sec})$ & $T_{p}(\sec )$ \\
\hline Chi-chi 1 & 0.2296 & 47.99 & 8.015 \\
\hline Chi-chi 2 & 0.2167 & 74.985 & 11.94 \\
\hline Chi-chi 3 & 02061 & 86.485 & 17.615 \\
\hline Chi-chi 4 & 0.2252 & 124.06 & 10.04 \\
\hline Chi-chi 5 & 0.2779 & 65.005 & 5.8 \\
\hline Chi-chi 6 & 0.2347 & 68.03 & 15.22 \\
\hline Chi-chi 7 & 0.2678 & 68.03 & 15.39 \\
\hline Chi-chi 8 & 0.2818 & 74.98 & 12.15 \\
\hline Chi-chi 9 & 0.2164 & 77.49 & 19.62 \\
\hline Chi-chi 10 & 0.2465 & 63.985 & 1428 \\
\hline Chi-chi 11 & 0.2504 & 139.98 & 36.02 \\
\hline Chi-chi 12 & 0.2021 & 122.97 & 37.19 \\
\hline Chi-chi 13 & 0.2449 & 149.97 & 37.53 \\
\hline Chi-chi 14 & 0.2206 & 143.97 & 31.98 \\
\hline Chi-chi 15 & 0.201 & 139.98 & 20.14 \\
\hline Chi-chi 16 & 0.2515 & 149.97 & 46.14 \\
\hline Chi-chi 17 & 0.2828 & 149.97 & 33.97 \\
\hline Chi-chi 18 & 0.2820 & 149.97 & 34.05 \\
\hline Chi-chi 19 & 0.2656 & 60.03 & 10.965 \\
\hline Chi-chi 20 & 0.2598 & 149.97 & 47.37 \\
\hline Chi-chi 21 & 0.2229 & 149.97 & 29.39 \\
\hline Chi-chi 22 & 0.2270 & 149.97 & 37.37 \\
\hline Chi-chi 23 & 0.201 & 119.976 & 31.64 \\
\hline Chi-chi 24 & 0.2596 & 119.976 & 36.688 \\
\hline
\end{tabular}

In these tables, $\mathrm{T}$ represents the total recorded period and $T_{p}$ represents the time when peak acceleration occurs.

\section{Analysis based on the Finite Element Method}

The analysis of all RC frame models has been done by finite element method (e.g. Etabs v2016). It is a numerical technique to solve the frame models into elements models. Linear time history method is used in different models explained in Agrahari et al. [28]. The fixed support condition is assigned at the joint base of the structures, and the soil type is hard. A large number of near field time history data $(0.01 \mathrm{~g}$ to $0.32 \mathrm{~g})$ is considered and also the fundamental natural period of the structure is taken up to $1.5 \mathrm{sec}$.

\section{Results and Discussion}

\subsection{Floor Spectral Acceleration}

For performing the dynamic analysis, selected horizontal time history is applied at a different level for each model. For obtaining the floor spectral acceleration, ground acceleration with 5\% damping is considered in the present work. The mean spectral acceleration of each model for the ground motion range of $0.2 \mathrm{~g}$ to $0.32 \mathrm{~g}$ is shown in Figure 2. From the figure, it is seen that, as the height of the building increases, the amplification value decreases. It is also observed that for the building period is less than $0.5 \mathrm{sec}$, the spectral acceleration values are higher. 


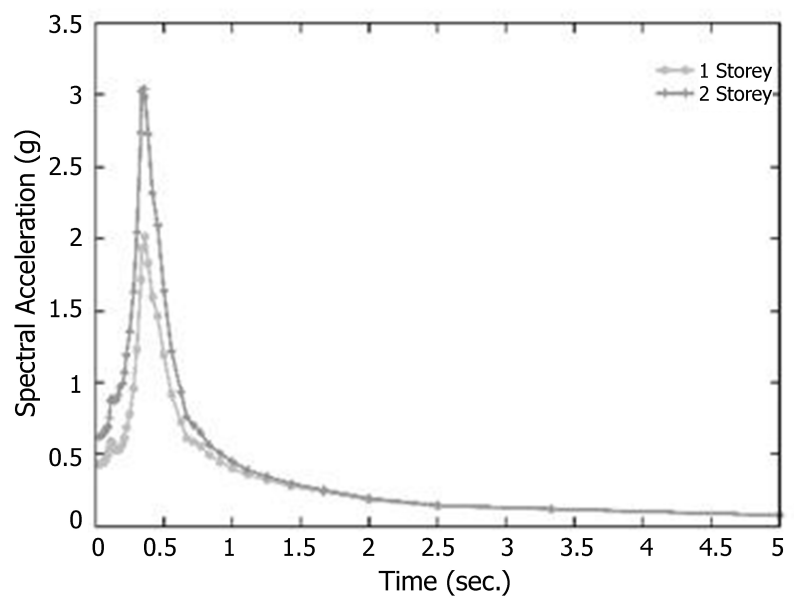

(a)

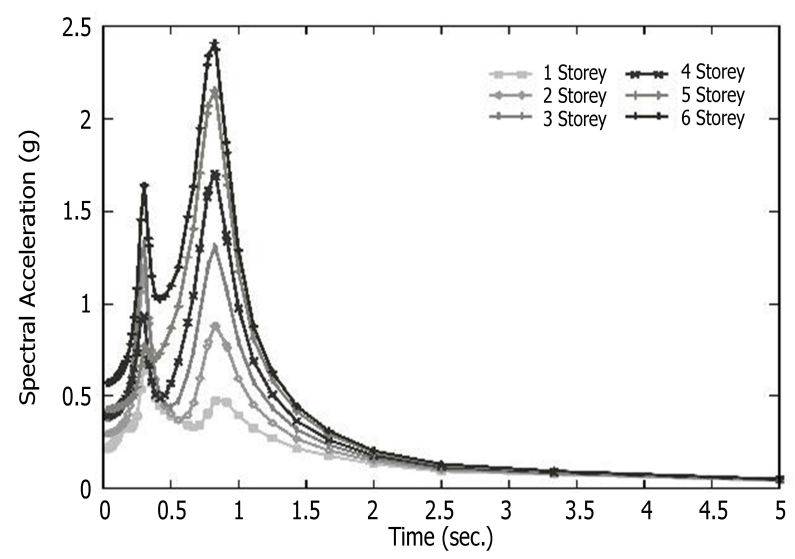

(c)

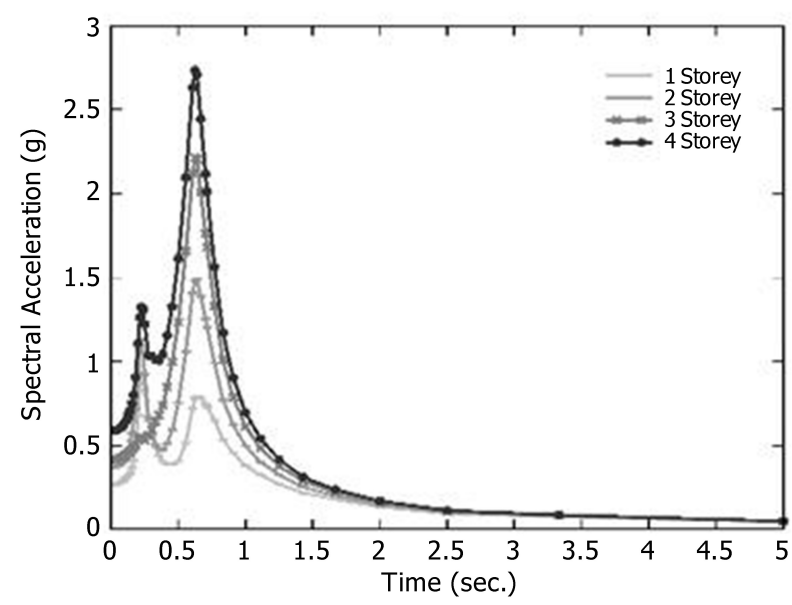

(b)

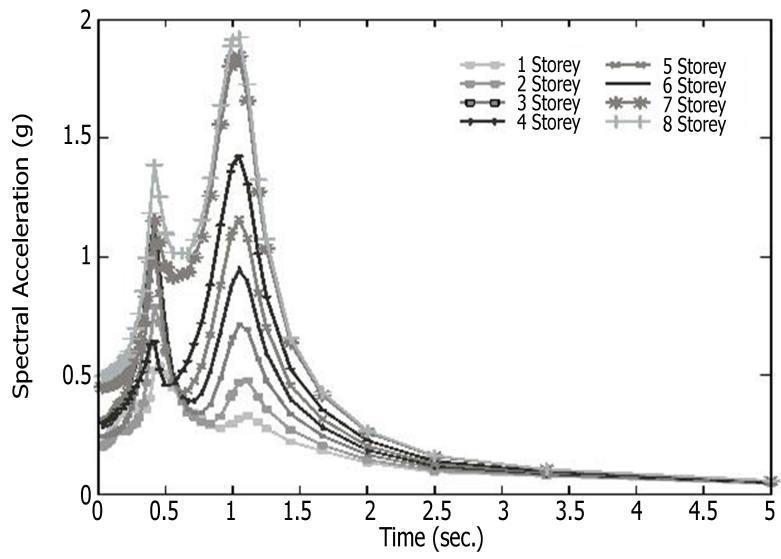

(d)

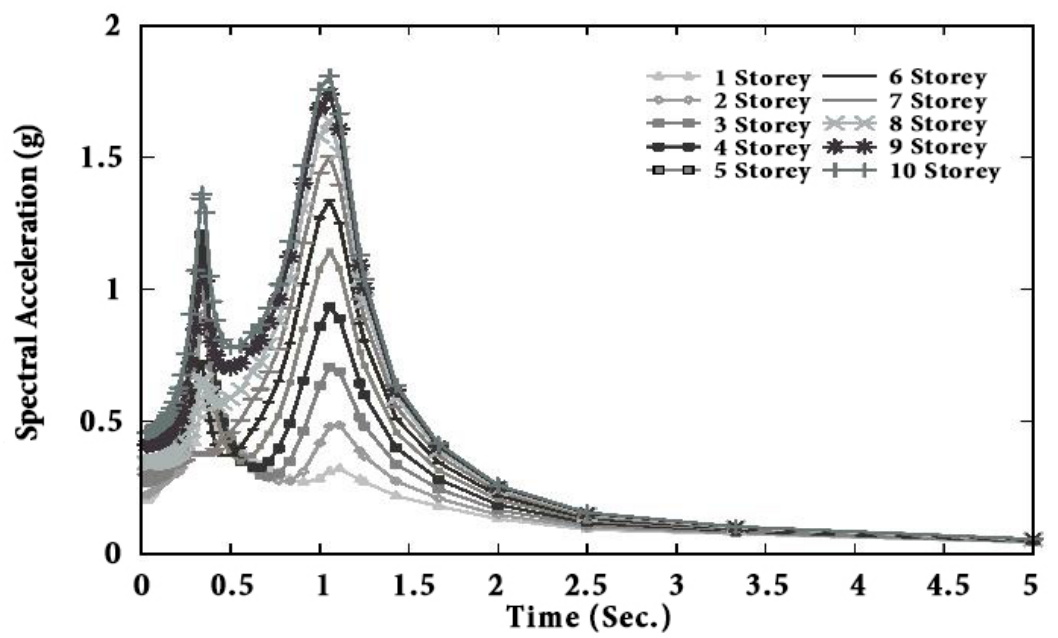

(e)

Figure 2. Mean floor spectral acceleration for ground motion range $0.2 \mathrm{~g}$ to $0.31 \mathrm{~g}$ (a) 2 storey (b) 4 storey (c) 6 storey (d) 8 storey (e) 10 storey 

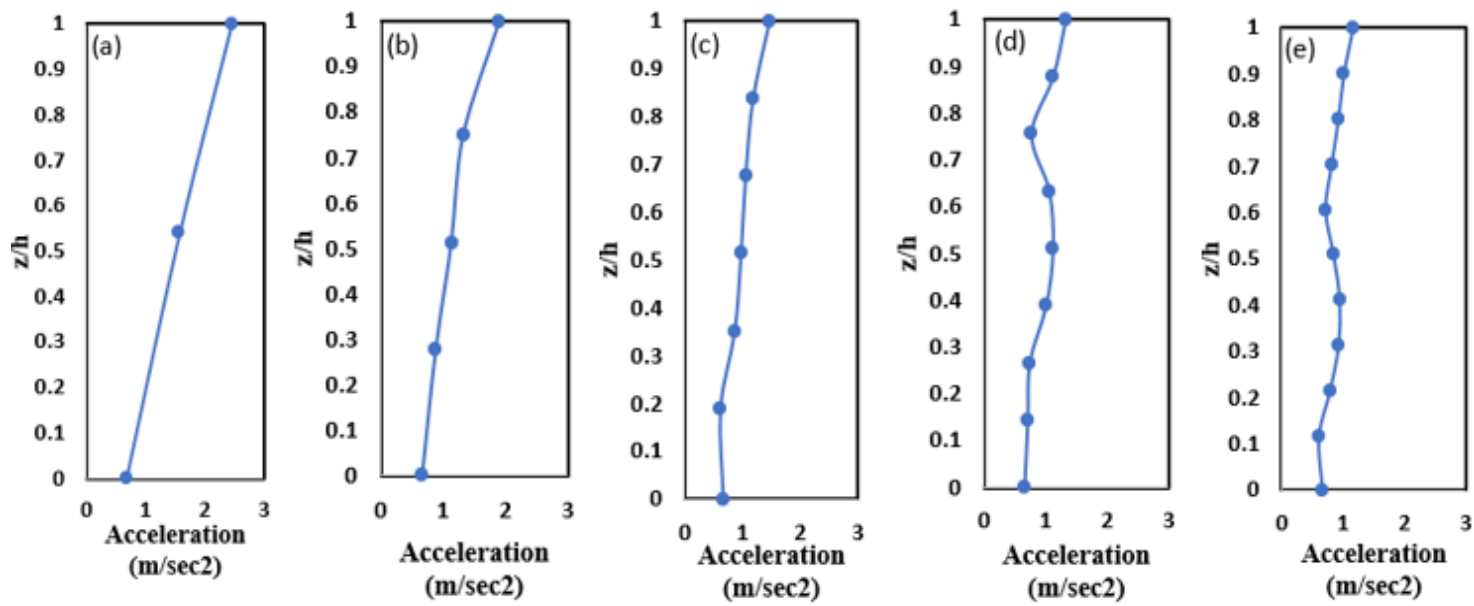

Figure 3. Behavior of floor acceleration for ground motion 0.06g (a) 2 (b) 4 (c) 6 (d) 8 and (e) 10 stories
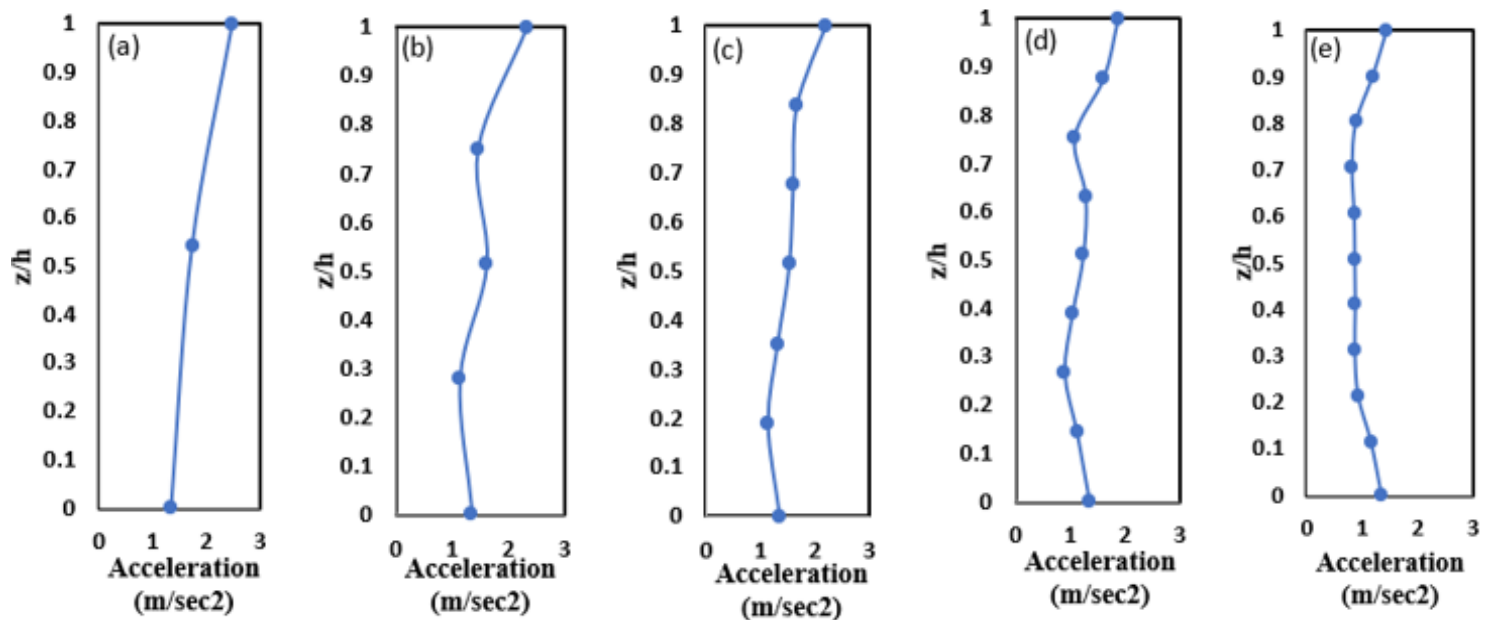

Figure 4. Behavior of floor acceleration for ground motion $0.16 \mathrm{~g}$ (a) 2 (b) 4 (c) 6 (d) 8 and (e) 10 stories
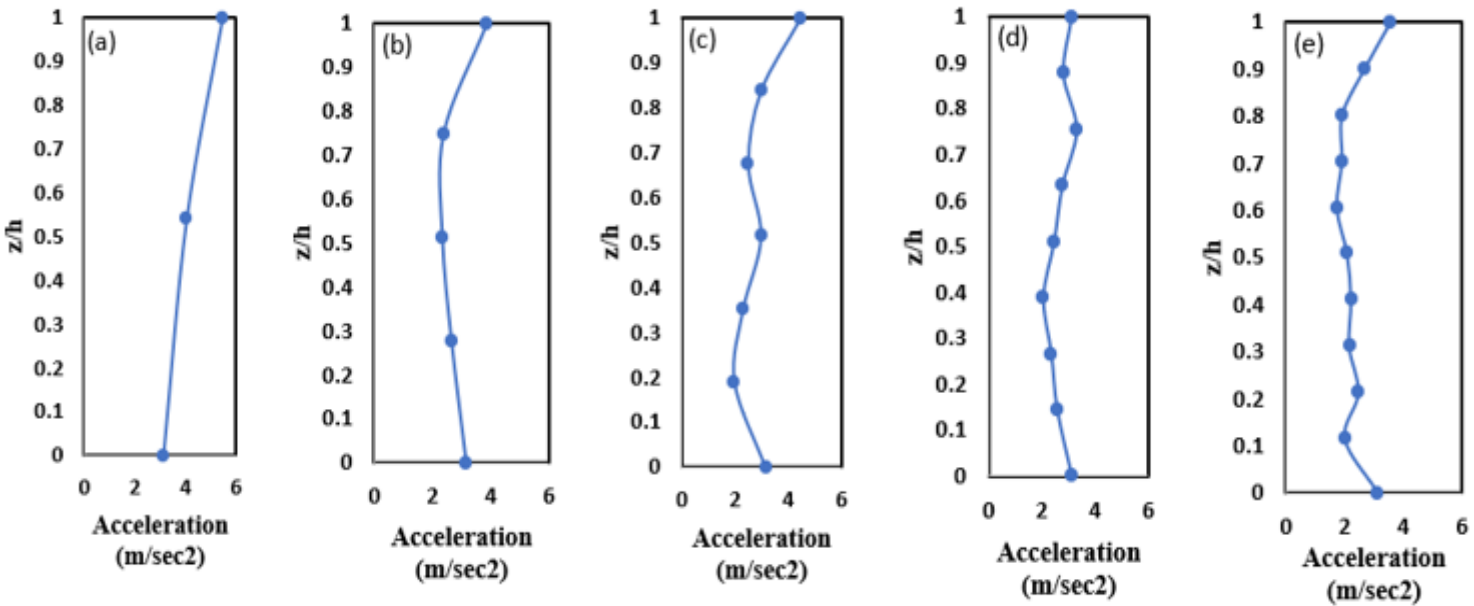

Figure 5. Behavior of floor acceleration for ground motion 0.32g (a) 2 (b) 4 (c) 6 (d) 8 and (e) 10 stories 


\subsection{Comparison of Peak Floor Acceleration}

The peak floor acceleration is used to define the seismic demands on rigid or semi-rigid (when frequencies of vibration more than $20 \mathrm{~Hz}$ ) acceleration sensitive NSCs. However, for flexible NSCs, the acceleration is different from the peak floor acceleration. Figures 3-5 shows the comparison of the $5 \%$ damped floor acceleration, for the various heights of buildings during the Chi-Chi earthquake. The PGA of Chi-Chi earthquake time histories are $0.06 \mathrm{~g}, 0.16 \mathrm{~g}$ and $0.32 \mathrm{~g}$, respectively. For the fundamental period of the building is less than $0.5 \mathrm{sec}$. the peak floor acceleration is approximately 3.5,2 and 1.5 times higher than the PGA for $0.06 \mathrm{~g}, 0.16 \mathrm{~g}$ and $0.32 \mathrm{~g}$, respectively. However, the increment is $3,1.8$ and 1.3 times the peak ground acceleration when the building period lies in the range of 0.5 to $1 \mathrm{sec}$. For higher building period (more than $1 \mathrm{sec}$ ), the peak floor acceleration is approximately 2, 1.5 and 1.3 times the peak ground accelerations having PGA of $0.06 \mathrm{~g}, 0.16 \mathrm{~g}$, and $0.32 \mathrm{~g}$, respectively. Moreover, when the PGA of the ground motion increases, the peak floor acceleration decreases. It is also observed that when the building period increases, the peak floor acceleration decreases.

\subsection{Effect of Building Period to Amplification Factor}

Based on linear time history method, the acceleration amplification factor depends on the fundamental period of the building. Figure 6 illustrates the mean and Mean + SD of PFA/PGA for each of the five buildings. From comparison of the PFA/PGA values with ASCE code, it can observe that PFA/PGA values are constant for various natural periods of structures for ASCE model. However, Fathali's model showed that the PFA/PGA values are not consistent, and its values are different for different building period.

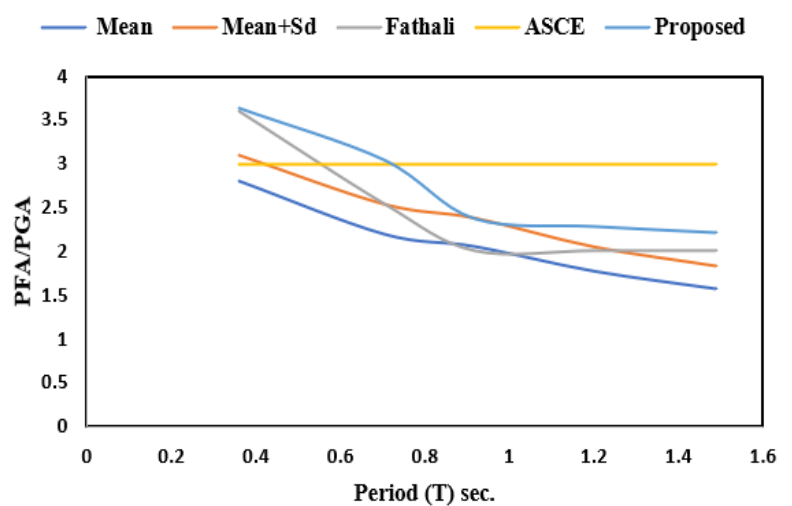

Figure 6. Comparison of building period to PFA/PGA with different models

\subsection{Comparison of the Amplification Factor with Different Models}

Comparison with the proposed model, ASCE, Fathali's non-linear mathematical model and the Mean + SD results, are shown in Figure 7, 8 and 9 respectively. 

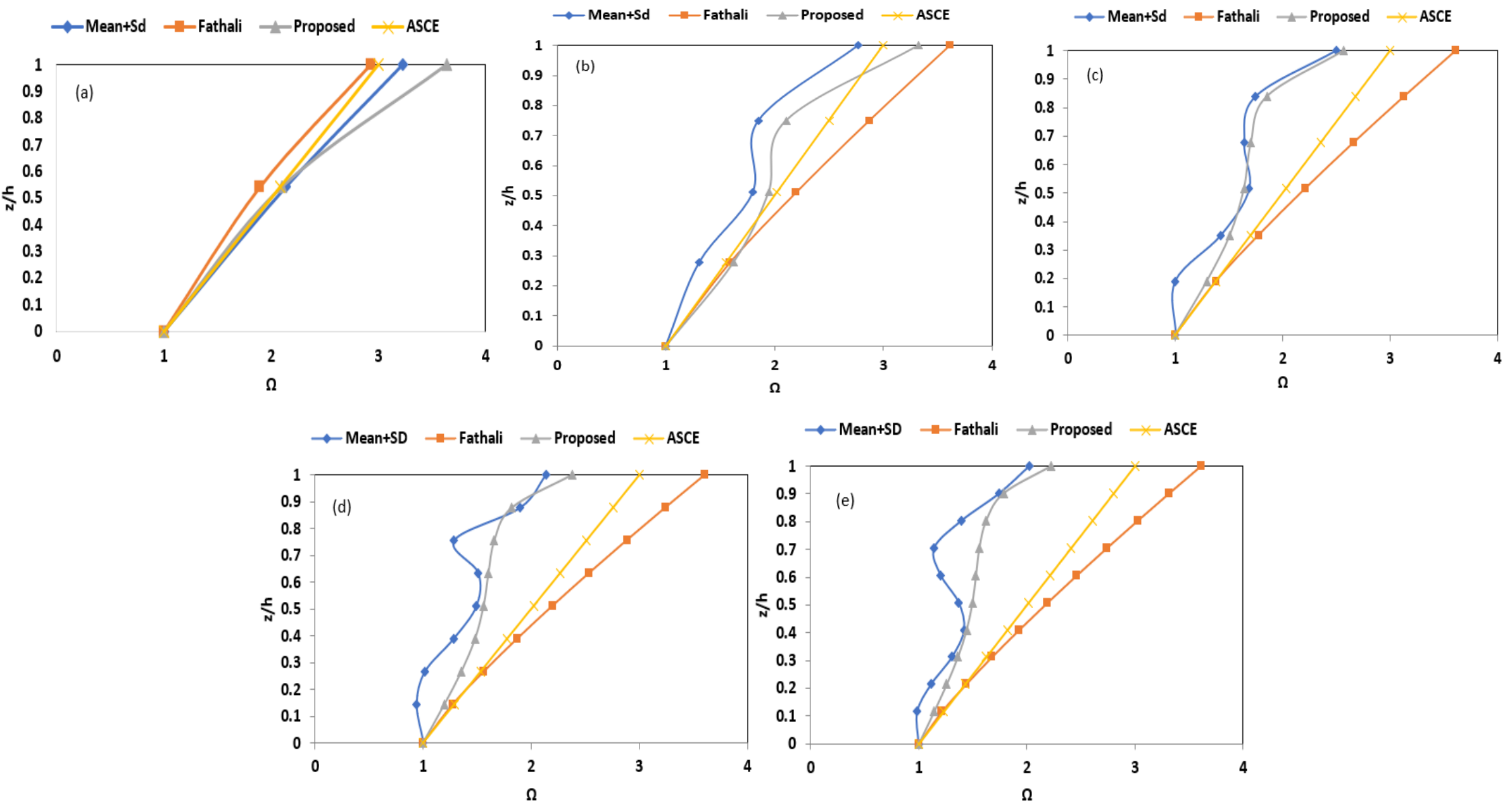

Figure 7. Comparisons between acceleration amplification factor to normalized height when ground motion ranges less than $0.067 \mathrm{~g}$ (a) 2 (b) 4 (c) 6 (d) 8 and (e) 10 stories

ASCE amplification model shows the linear behaviour as the natural period of the structure increases. For the natural period of the structure less than 0.5 sec, ASCE results observed that its values are $11.0 \%$ less than mean + standard deviation (Mean + SD). However, Fathali's model resulted 7.0\% less than the amplification factor for Mean + SD results. As the height of the building increases, the ASCE and Fathali's acceleration amplification models achieved conservative results. The proposed amplification model provided the values similar to the Mean + SD results. The shape of the curve from proposed model is also similar to the Mean + SD results as the height of the building increases. 

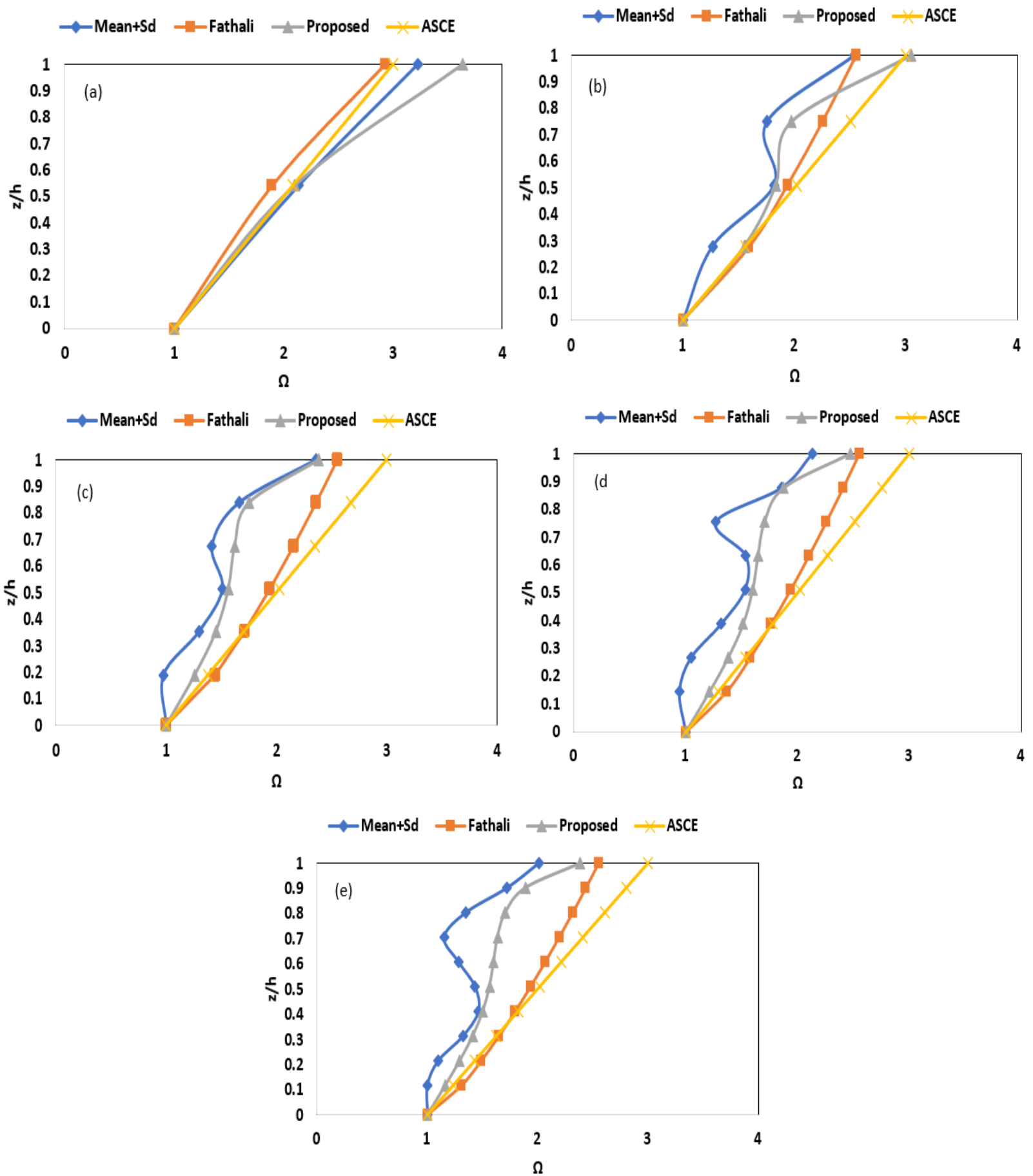

Figure 8. Comparisons between acceleration amplification factor to normalized height when ground motion ranges are $0.067 \mathrm{~g}$ to $0.2 \mathrm{~g}$ (a) 2 (b) 4 (c) 6 (d) 8 and (e) 10 stories

For the ground motion range from $0.067 \mathrm{~g}$ to $0.2 \mathrm{~g}$, the Fathali's model overestimated the amplification factors when the normalized height of the building is higher than 0.5 . The difference between Mean $+\mathrm{SD}$ amplification and ASCE model's amplification values increases as the fundamental period of the building increases. Fathali's and ASCE amplification models are approximate $28 \%$ and $50 \%$ higher than the Mean + SD results as the natural period of the building increases up to $1.5 \mathrm{sec}$. Though, the proposed amplification model obtained values $15 \%$ higher than Mean + SD results. The performance of the proposed model is similar to the Mean + SD amplification results. 

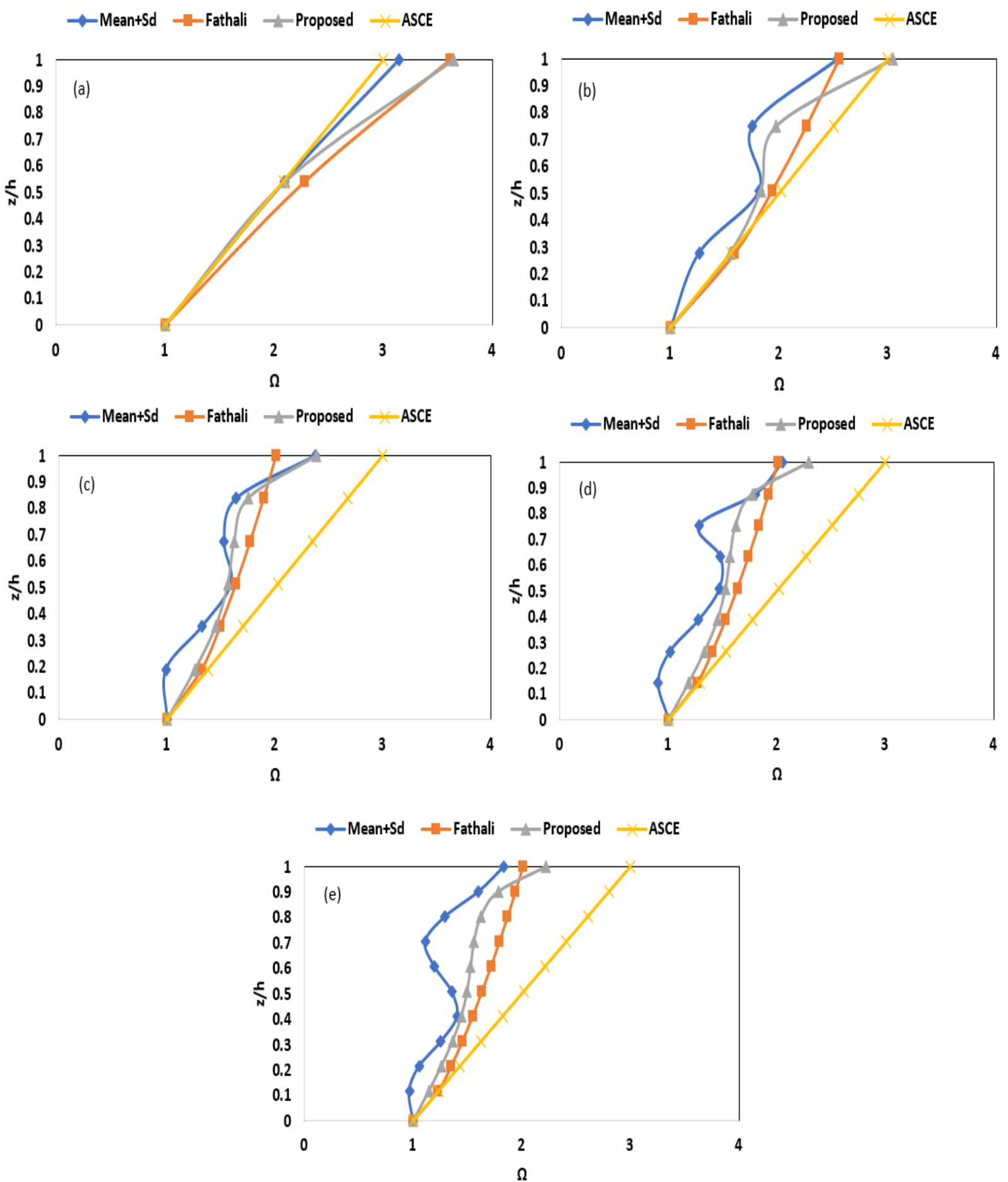

Figure 9. Comparisons between acceleration amplification factor to normalised height when ground motion ranges are $0.2 \mathrm{~g}$ to $0.32 \mathrm{~g}$ (a) 2 (b) 4 (c) 6 (d) 8 and (e) 10 stories

When the ground motion range is between $0.2 \mathrm{~g}$ to $0.32 \mathrm{~g}$, the amplification values of the Fathali's model is around $15 \%$ higher than the Mean + SD results. For this ground motion range $(0.2 \mathrm{~g}$ to $0.32 \mathrm{~g})$ Fathali's model gave better results, but the deviation from Mean + SD results increases as the normalized height goes higher than 0.5. As the fundamental period of the building rises, the amplification values of Mean + SD falls. However, ASCE model observed that amplification factor varies linearly as the height of the building increases and its maximum values at the top of the building is 3 . The amplification factor results obtained by ASCE code are approximate $60 \%$ higher than the Mean + SD results. The results observed by the proposed model are approximately $10 \%$ to $20 \%$ higher than Mean $+\mathrm{SD}$ results. The behavior of the proposed model is very close to the behavior of Mean + 
SD results, respectively.

\subsection{Comparison of Component Amplification Factors}

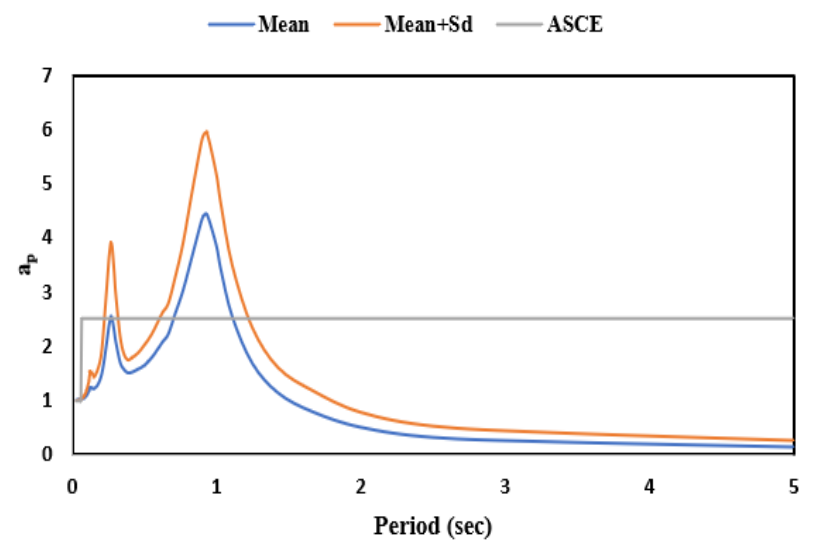

Figure 10. Comparison of actual and ASCE ap spectra based on 30 floor acceleration histories recorded in 4 Storey building under earthquakes with PGA $>0.2 \mathrm{~g}$.

The component amplification factor $\left(a_{\mathrm{p}}\right)$ refers to the dynamic amplification of NSCs compared to PFA. The component amplification factor is defined as the ratio between FRS/PFA. ASCE code defines $a_{p}$ is 1 for rigid components (those components having a natural period less than $0.06 \mathrm{sec}$.) and 2.5 for flexible components (those with a natural period higher than $0.06 \mathrm{sec}$ ). From figure 10, it can observe that the codal values gave conservative results when the component period is higher than $0.25 \mathrm{sec}$. For flexible components, $a_{\mathrm{p}}$ values observed from the Mean + SD component amplification results are approximately 2 to 2.5 times higher than the ASCE codal results.

From the comparison of the proposed model and the previous research model, it is found that the ASCE amplification factor formula gives significant results when the period of the structure is less than 0.5 second. ASCE formula provided conservative results when the period of the structure higher than 0.5 seconds. Fathali's model notify better results as compared to the ASCE code when the ground motion acceleration range is between $0.067 \mathrm{~g}$ to $0.32 \mathrm{~g}$. The difference of amplification values between the Mean + SD and Fathali's model results are increasing between the ground motion range of $0.01 \mathrm{~g}$ to $0.067 \mathrm{~g}$, respectively. However, the proposed model gives more realistic results compared to the other models.

\section{Conclusions}

In this paper, five moment-resisting RC frame models having different heights are considered. Building frames are analyzed using linear time history method, with an observed large number of time history data having ranges less than $0.067 \mathrm{~g}, 0.067 \mathrm{~g}$ to $0.2 \mathrm{~g}$ and $0.2 \mathrm{~g}$ to $0.32 \mathrm{~g}$ respectively. To get the actual PFA and PGA values and with the help of these data, a non- linear acceleration amplification formula is proposed and compared with the previously reported models. It is found that:

- ASCE formula provide better results when the period of the structure is less than 1.0 second. After that, it performed conservatively.

- The Fathali's model showed promising results to ASCE. It gave obscure results when ground motion lies $0.01 \mathrm{~g}$ to $0.067 \mathrm{~g}$.

- In many cases, the Fathali's model provide better results at the roof of the building, but for other storeys, it is less satisfactory.

- The shape of the amplification factor obtained by the proposed model is close to the shape of the Mean + SD results.

- The $\mathrm{a}_{\mathrm{p}}$ values given by the ASCE is conservative and its values are 2 to 2.5 times lower than Mean $+\mathrm{SD}$ results at sometimes.

- On comparing the previous mathematical model, propose non-linear amplification models give more realistic results to Mean $+\mathrm{SD}$ results.

\section{REFERENCES}

[1] Sin M. N, Jacques A. and Chung P.C. "Earthquake cycle in Western Taiwan: Insights from historical seismicit", Geophysical Journal International, Vol. 178, 2009, pp. 753774, doi: 10.1111/j.1365-246X.2009.04164.x

[2] Amalia A., and Iranata D. Alternative Design of Post-Earthquake Temporary Housing in Indonesia, Civil Engineering and Architecture, Vol. 8, No. 3, 2020, pp. 289 296, DOI: $10.13189 /$ cea.2020.080312.

[3] Tsai K.C, Chaing P.H, Bruneau M. "Overview of building damages in 921 chi-chi Earthquake" Earthquake Engineering and Engineering Seismology, vol. 2, no. 1, pp. 93-108, March 2000

[4] Ayers J. M, Sun T. Y, and Brown F. R "Non-structural Damage to Buildings. The Great Alaska Earthquake of 1964: Engineering", National Academy of Science, Washington, DC., 1973

[5] Soong T. T, "Seismic Performance of Non-structural Elements during the Loma Prieta Earthquake," Proc. 22nd Joint Meeting U.S.-Japan Cooperative Program in Natural Resources Panel on Wind and Seismic Effects, Report NIST SP 796, 1990, National Institute of Standards and Technology, Gaithersburg, Maryland, pp. 331-336.

[6] Rihal S. S, "Performance and behavior of non-structural building components during the Whittier Narrows, California (1987) and Loma Prieta, California (1989) earthquakes: Selected case studies," Proc. Seminar and Workshop on Seismic Design and Performance of Equipment and Non-structural Elements in Buildings and Industrial Structures (ATC-29), 1992, Applied Technology Council, Redwood City, California, pp. 119-143

[7] Whitman R. V., Hong S. T, and Reed J. "Damage statics for 
high-rise buildings in the vicinity of the San Fernando earthquake," Report No. 7, Massachusetts Institute of Technology, Cambridge, Massachusetts, 204.

[8] Reitherman R. and Sabol T. A., "Northridge earthquake of January 17, 1994: reconnaissance report-Non-structural damage," Earthquake Spectra, EERI 11(Supp), pp. 453-514, 1995

[9] Phipps M. T., "The impact of non-structural damage on building performance: Reflections on the 1994 northridge earthquake," Report UCB/EERC-97/05, The EERC-CUREE Symposium in Honor of Vitelmo V. Bertero, Earthquake Engineering Research Centre, University of California, Berkeley, California, 1997, pp. 173-178.

[10] Dhakal R. P., "Damage to non-structural components and contents in 2010 Darfield earthquake," Bulletin of the NewZeland Society for Earthquake Engineering, 2010, vol. 43, no. 4, pp. 404-411.

[11] Perrone, D., Calvi, P. M., Nascimbene, R., Fischer, E. and Magliulo, G. "Seismic performance and damage observation of nonstructural elements during the 2016 Central Italy Earthquake," Bulletin of Earthquake Engineering, 2018, doi:10.1007/s10518-018-0361-5.

[12] Miranda E, Mosqueda G, Retamales R and Pekcan G, "Performance of nonstructural components during the 27 February 2010 Chile earthquake". Earthquake Spectra, 2012, vol. 28, pp. 453-71.

[13] MacRae GA, Pampanin S, Dhakal R, Palermo A, Baird A and Tasligedik $S$ "Review of Design and Installation Practices for Nonstructural Components", Report prepared for the Engineering Advisory Group of the Department of Building and Housing by New Zealand Consultants, Industry and Related Experts, NZ, June 2012.

[14] Flores X F, Diego G L and Finley C A, “Assessment of floor accelerations in special steel moment frames, Journal of Constructional Steel Research, 2015, vol.106, pp. 154165

[15] Mahin L J., "Seismic response of light subsystems on inelastic structures" J Struct Eng, 1985, vol. 111, pp. 40017.

[16] Taghavi S and Miranda E., Response assessment of nonstructural building elements, Report No. PEER 2003/05. Richmond, CA: Dept. of Civil and Environmental Engineering,Stanford University, Stanford, CA. Pacific Earthquake Engineering Research Center, 2003

[17] American Society of Civil Engineers (ASCE), 2010
Minimum Design Loads for Buildings and Other Structures, ASCE7-10, Reston, VA.

[18] Drake R M and Bachman R E., NEHRP Provisions for 1994 for Non-Structural Components, Journal of Architectural Engineering, 1996, vol. 2, no. 1, pp.26-31 DOI: 10.1061/(ASCE)1076-0431(1996)2:1(26)

[19] Gillengerten J D and Bachman R E,, "Background on the Development of the NEHRP Seismic Provisions for Non-Structural Components," in Proceedings of the 2003 ASCE/SEI Structures Congress and Exposition, Seattle, Washington, 2003

[20] American Society of Civil Engineers (ASCE), 2005.Minimum Design Loads for Buildings and Other Structures, ASCE7-05, Reston, VA.

[21] Fathali S and Lizundia B, "Evaluation of Current Seismic Design Equations for Non-Structural Components in Tall Buildings using Strong Motion Records", Wiley Online Library, 2011, vol. 20, pp. 30-46 DOI: 10.1002/tal.73614.

[22] Crescenzo P, Gennaro M, Maddalena C and Gaetano M, "Evaluation of the Seismic Demand on Acceleration sensitive Nonstructural Components in RC Frame Structures", Second European Conference on Earthquake Engineering and Seismology, Istanbul AUG. 25-29, 2014, DOI: $10.13140 / 2.1 .3121 .0244$

[23] Surana M, Singh Y and Lang D H., "Effect of Response Reduction Factor on Peak Floor Acceleration Demand in Mid-Rise RC Buildings", J. Inst. Eng. India Ser. A, 2017, vol. 98 , no. 1 , pp. 53-65, DOI 10.1007/s40030-017-0202-6

[24] Wieser J, Pekcan G, Zaghi A E, Itani A, and Maragakis M, "Floor accelerations in yielding special moment resisting frame structures," Earthq. Spectra, 2013, vol. 29, no. 3, pp. 987-1002.

[25] User manual Eureqa: The A.I.-Powered Modeling Engine (2009)

[26] ETABs, Extended 3D (Three-Dimensional) Analysis of Building Systems. Integrated Analysis, Design and Drafting of Building System, Advanced ver. 16.2.0 Computers and Structures. Inc. CSI, Berkeley, Calif., 2016

[27] Strong ground motion, https://strongmotioncenter.org/vdc/ scripts/default.plx

[28] Agrahari R K., Sharma A, and Pathak K K,"Seismic Acceleration Amplification Factor Model for Non-Structural Components in RC Frame Structures", Journal of Structural Engineering, 2020, vol. 47, no. 3, pp181-19 